\title{
The Influence of Urban Poverty on Students' Academic Optimism: Does Government Assistance Play a Role?
}

\author{
Azam Othman \\ Kulliyyah of Education, \\ International Islamic University Malaysia, \\ Kuala Lumpur, Malaysia \\ azam_othman@iium.edu.my \\ Suhailah Hussien \\ Kulliyyah of Education, \\ International Islamic University Malaysia, \\ Kuala Lumpur, Malaysia \\ suhailah@iium.edu.my \\ Norbaiduri Ruslan \\ Kulliyyah Of Islamic Revealed Knowledge \\ And Human Sciences, \\ International Islamic University Malaysia, \\ Kuala Lumpur, Malaysia \\ norbaiduri@iium.edu.my
}

\author{
Hairuddin Mohd Ali \\ Kulliyyah of Education, \\ International Islamic University Malaysia, \\ Kuala Lumpur, Malaysia \\ hairuddin@iium.edu.my \\ Moha Asri Abdullah \\ Kulliyyah Of Economics and Management \\ Sciences, \\ International Islamic University Malaysia, \\ Kuala Lumpur, Malaysia \\ mosri@iium.edu.my \\ Merah Souad \\ Kulliyyah of Education, \\ International Islamic University Malaysia, \\ Kuala Lumpur, Malaysia \\ souad@iium.edu.my
}

\begin{abstract}
The present study investigated the relationship between urban poor students' perceptions of government assistance and poverty and their level of academic optimism. A survey was administered to 500 urban poor students in two major Malaysian cities, Kuala Lumpur and Johor Bahru. The students were identified and randomly selected for the study with the help of their respective schools. AMOS version 24 was used to test the hypothesised model using Structural Equation Modelling (SEM). The findings revealed a significant direct association between students' perceptions of poverty and academic optimism. However, no significant indirect influence was found between students' perceptions of poverty and their academic optimism through government assistance. These findings suggest that government assistance programmes are not necessarily a contributor to students' academic optimism. The lack of any significant influence between students' perceptions of poverty and academic optimism, through government assistance, may indicate a need to re-evaluate the existing assistance programmes rendered by the government to students in the urban poor category.
\end{abstract}

Keywords: Malaysia, government assistance programmes, students' perceptions of poverty, academic optimism, urban poverty, secondary school 


\section{INTRODUCTION}

In the process of gaining a significant place among the educational hubs at the global level, Malaysian government, every year, allocates the highest budget for the education sector, reflecting its serious commitment to this aim. This places Malaysian educational system almost at the same level with other developed countries. Maintaining higher educational growth and expansion in Malaysia requires students' motivation towards the enrolment and retention until the graduation period, and this is a concern of the government and other education stakeholders. Motivation for higher education (MFHE) in the context of this study refers to intrinsic motivation of International Islamic University Malaysia (IIUM) students towards higher education. In other words, MFHE indicates the internal willingness of IIUM students towards attaining higher education.

The developing world is becoming more urban due to the push and pull factors between rural and urban areas. Urbanisation increases as more people leave their villages in search for better life opportunities, jobs, education, and services in big towns and cities. However, this internal exodus does not necessarily mean that people themselves are becoming urbanised. Ravallion (1997) explained that a country's urbanisation opens the door for more overcrowded and unplanned slum areas surrounding big cities and metropolitans. This will lead to the creation of ghettos where poverty is rampant, in addition to the lack of basic services and security which is already paving the way for crime rates to rise.

Mathur (2013) added that urban poverty often brings with it other hardships, such as shelter deprivation, informality, worsening of the living conditions, increased risks due to climate change, and exclusionary urban forms. Some may explain that urban poverty has a negative impact on developing countries' efforts to urbanize life. The irony here is that urbanisation itself is part of the poverty reduction plans in these countries since the rise of industrialised economies is the outcome of the countries' shifting their focus gradually from agriculture to more remunerative income-generating activities, manufacturing and other services which offer better-waged employment (Ravallion, 1997). Garland et al. (2007) added that hundreds of millions of people who live in cities across the globe-especially in underdeveloped and developing countries - are living in desperate poverty without proper access to adequate shelter, clean water, and basic sanitation despite the rapid urbanisation process taking place.

A report by the World Bank indicated that poverty has become an urban phenomenon in the developing world (Liddle, 2017). People in big cities are classified according to their income brackets and living conditions. Urbanisation efforts in developing countries are crippled by urban growth. A new class of the urban poor emerges and creates social, economic, and educational challenges to urban planning. This is a critical problem in many countries. For instance, China, the world's largest nation of 1.393 billion people (in 2018) is also being confronted by the phenomenon of urban poverty (Mathur, 2013) despite it being one of the biggest economies at present. Correspondingly, based on the same urgency and importance, a study of urban poverty in Malaysia (Mok et al., 2007) must be conducted as the acceleration of 
urbanisation has caused social inequality and physical change in the country's urban landscapes and environments.

One of the sectors substantially impacted by the social and economic inequalities characteristic of urban areas is the school system where students' aspirations, academic optimism, and academic achievements are intricately tethered to these inequalities. Studentsbe they rich or poor; urban or rural - all aspire to excel in their education, although they may differ in terms of aspirations and educational goals. A study by Beauvais (1993) on American urban poor students found that black students had the same level of aspiration as white students. However, in general, the score and achievement levels between the black and white urban students were remarkably unequal. Black urban students were shown to hold unrealistic aspirations of education which made it difficult for them to succeed in their studies. Furthermore, the educational aspirations of low- and middle-status children were dissimilar following the impact of poverty on their self-esteem, which in turn gave way to self-fulfilling prophecy. Chang (2008) revealed that most urban students in high schools perceived the campus community or culture, leadership and curriculum as factors that contributed to their academic achievement. Middle-status children were better able to achieve their long-range academic goals when compared to low-status children because the former often benefit from the coordinated efforts of their parents and teachers, as well as from additional school aids and resources, besides living in better and more conducive conditions. Thus, with enough resources and support, students have higher chances of achieving their goals and of succeeding academically.

Since its independence in 1957, Malaysia has managed to reduce poverty and income inequality among its citizens. A federal report published by the Economic Planning Unit of the Prime Minister's Department (2004) interestingly stated that reducing inequality among Malaysians could simultaneously promote social harmony and bring about rapid growth to the economy. In another statement, Aziz (2015) indicated that Malaysia's poverty rate significantly declined from $49.3 \%$ in 1970 to $29.2 \%$ in 1980 as a result of the 1971-1990 implementation of the New Economic Policy (NEP), which helped to decrease poverty. It was the focus of this policy to eradicate poverty among all Malaysians regardless of ethnicity and religion (Economic Planning Unit, 2018). Another policy that directly addressed the creation of a balanced income distribution among Malaysians was the 1991-2000 National Development Policy.

The period of 1971 to 2000 was a very complex and challenging time for Malaysia (Economic Planning Unit, 2004). The government needed to manage and plan for the different economic sectors to develop the nation and provide better living conditions for its citizens. Initially, from the 1970s to the 1980s, the specific aims of the NEP were to eradicate poverty in rural constituencies. However, the aims later shifted gradually to include urban areas due to the rapid industrialization and urbanization that was highly concentrated in major urban concentrations such as the Klang Valley, Penang, and Johor (Hatta \& Ali, 2013). Hatta and Ali (2013) further elaborated that to eradicate poverty in both urban and rural settings, the economy must be strengthened by expanding economic transactions, and subsidies needed to be given to the poor to reduce all sorts of socioeconomic inequalities among the different ethnicities, i.e., 
Chinese and Indians, and other than Bumiputera ethnic groups. Under this plan, the government focused on two main objectives, which included giving equal opportunities to all groups providing a social safety net for the disadvantaged groups, and giving equitable access to health, education, and basic infrastructure to all groups.

In the education sector, the issue of urban poverty and schooling in Malaysia is impacting students in major cities. Urban schools located in large low-income population areas were reported to have an approximately $87 \%$ attendance level (Che Mat, 2017). The relatively high level of absenteeism has negatively affected the academic achievement of urban poor students. In addition, Hong (2017) found that most teachers in urban schools perceived that poor urban students' underachievement was related to external factors that included social class, family background and their general living conditions, such as the lack of parental support, technology, funds, and ability, in addition to economic struggles of the home and the school. All these factors were perceived to be responsible for the decline of students' aspirations in schools and influence their efforts, motivation, and academic performance.

Considering these factors, the Malaysian government has formulated specific initiatives to cope with the problem of poverty among school students. For example, the Malaysian government is continuously assisting the underprivileged segment of society for capacitybuilding purposes. Several ministries and government agencies including the Ministry of Education, the Prime Minister's Department, and the Ministry of Women, Family, and Community Development have introduced financial assistance programmes meant for students from poor urban families. These assistance programmes include Bantuan Rakyat 1Malaysia (BR1M or 1Malaysia People's Assistance) and Kumpulan Wang Amanah Pelajar Miskin (KWAMP or Underprivileged Students' Trust Funds), as well as assistance that the students receive directly for their schooling needs (e.g., school meals and textbooks). But the effectiveness of these various aids is yet to be studied and evaluated.

There appears to be a lack of studies examining the effectiveness of federal assistance programmes in helping poor urban students in schools. Evaluating the effectiveness of these programmes would help the government and education authorities to better address the issues related to poor urban students. Furthermore, the lack of research on the impact of these assistance programmes on underprivileged students' academic well-being warrants a systematic and empirical study. Thus, the main aim of this paper is to present and discuss the findings of the current study, undertaken to examine the relationship between urban poverty, government assistance and students' level of academic optimism and their implications on school leaders. 


\section{LITERATURE REVIEW}

\section{Urban Poverty and Schooling}

Achievement disparities among school students are fundamentally related to family variables. A study conducted in primary schools in Ethiopia revealed that most of the respondent students dropped out of school due to their poor family background. Meanwhile, among students in the urban poor category, it was their perceptions of not having enough materials (e.g., clothes, shoes and learning materials) that had led them to discontinue their education in school (Tafere, 2012). Thus, it was not really poverty that had prevented the students from completing and getting an education. This led to the observation that urban poor students did not have a real interest in school and that they commonly had a lower interest in attending school. It came across that they were also not motivated to continue their formal learning and tend to withdraw from school at a very young age.

Capra (2009) observed that students from households that did not have a single member with a higher education background tend to assign less importance to attending school and pursuing an education in their lives. Hence, it was argued that teachers would play a critical role in turning these students around, fostering an academic interest in them, and encouraging them to perform well in education. It is generally agreed that teachers should ensure and monitor students' achievement by motivating and monitoring them closely inside and outside of the classroom, especially students who are from poor families.

According to Gehrke (2005), teachers teaching in schools for the urban poor need to have three important characteristics in order to be effective. The first characteristic is self-awareness or self-reflection, which essentially means that the teachers need to be aware of the capabilities of urban poor students. This characteristic is important for teachers to know the cultural and social identities of their students to avoid any misconception, as well as to gain a better understanding of students, their identities, and experiences. The second characteristic, as mentioned by Gehrke, is that teachers of the urban poor should accommodate students' learning needs with a strong knowledge base. A strong knowledge base helps teachers to utilise the specific resources available in their surroundings, deal with students affected by poverty, and respond effectively by taking actions to assist the students and community. The third characteristic is teachers of the urban poor should essentially have high expectations of all students regardless of where they are teaching or the backgrounds of their students. There is a strong relationship between students' engagement and teachers' efficacy (Sezgin \& Erdogan, 2015). Teachers who perform their duties diligently and professionally will likely show concern towards their students, which in turn would inspire the students to give more attention to their studies and improve their academic performance. At the same time, parents' aspirations could influence students' aspirations in academics. Therefore, both parents and teachers are the main social agents critical to the building of students' academic aspirations, alongside the community and neighbourhood, agencies, schools, and workplaces (Cabinet Office, 2008). Aspirations matter because they influence outcomes. 
The government assistance programmes are implemented to help students perform better in school and reduce their family's financial burden. Academically, urban poor families face the same financial issue and struggles as the rural poor. They often do not have additional resources to support their children's academic and financial needs. Some even lack the money for basic schooling needs such as school fees, daily stipends, or stationery. However, there is the issue of measuring the effectiveness of assistance programmes and determining how they impact the students at the receiving end. Academic achievement by means of examination results could be considered an indicator of effectiveness, but in terms of equity, it raises many questions. Chief among them is the degree of standardisation of the examinations. For instance, would there be variations in the exams' difficulty level if they were prepared by various individual schools instead of a standardised central body? Furthermore, can the impact of these assistance programmes be conceptualised fairly for students and schools of different levels?

The issue may not just be about academic levels but may encompass a larger and broader concern. Hoy et al. (2006) argue that academic optimism is a better measure for student success in school. Academic optimism has been shown to be a good predictor of school success regardless of the student's socioeconomic status (Gürol \& Kerimgil, 2010). Instead of focusing on the outcomes of education, academic optimism considers the potential that a school has, its students, and the parents. In this sense, academic optimism may offer a more universal approach for measuring the impact of assistance programmes because it does not depend solely on academic outcomes. It also takes into consideration the collective effort made by various parties instead of solely focusing on the teachers, in addition to factoring in aspects like support, efficacy, and trust (Hoy et al., 2006).

\section{Urban Poverty and Academic Optimism: The Conceptual Framework}

The Malaysian government is concerned with the well-being of poor students in public schools. To help students who are in need, several assistance programmes have been introduced to alleviate the financial burden of the students and their families. Despite these efforts, we are still not clear about the extent to which the assistance programmes have improved the recipient students' well-being, especially their academic achievement. The relationship between poverty and academic achievement is also yet to be thoroughly explored. Hence, this study proposed a conceptual framework (Figure 1) in an attempt to explain how poverty and government assistance programmes may work to influence students' academic optimism.

\section{Figure 1}

Urban Poverty and Academic Optimism: The Proposed Conceptual Framework

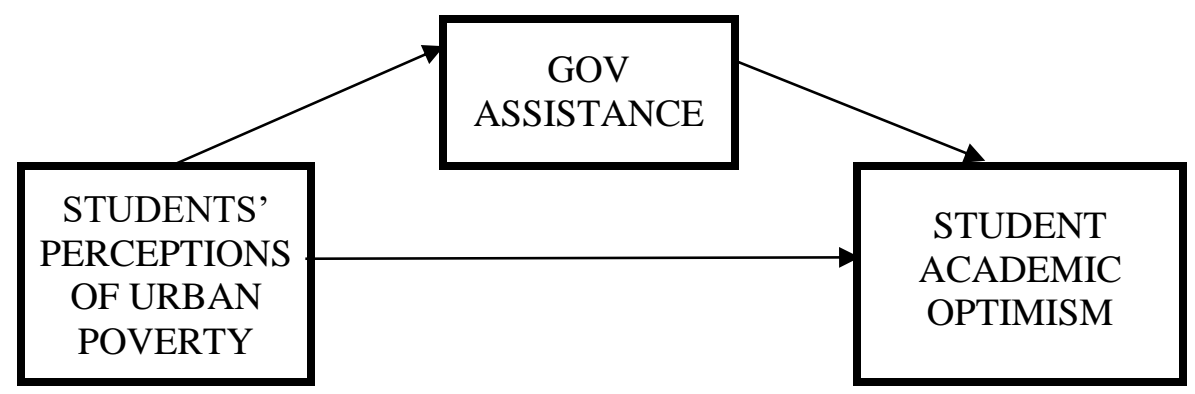


"Students' perceptions of urban poverty" is a construct based on the UK Poverty and Social Exclusion annual study, conducted by the Economic and Social Research Council (PSE, 2012. The Poverty and Social Exclusion annual study is a comprehensive study that covers various aspects of a household's economic status, including access to social services, health spending, education, parenting, employment, political engagement, and perceptions of poverty. This study was particularly interested in urban poor students' perceptions of poverty and how these perceptions might be related to government assistance programmes and the development of their academic optimism.

In the framework, the perceptions construct is further divided into the causes of poverty, society's view of people living in poverty, and the economic effects of poverty. Causes of poverty contain a list of statements on the students' views of why poverty occurs and continues to occur. Society's View (of People Living in Poverty) contains statements about how the students think they are viewed by other people in society. Economic Effects (of Poverty) are statements that reflect how poverty can economically affect the students and their familiesspecifically for students in the 15- to 17-year-old age group - by focusing on aspects related to the self and to family spending.

Government assistance is defined as the types of assistance programmes received by or rendered to the urban poor students. Appropriate and adequate government assistance has been shown to lead to better outcomes, such as higher rates of entry into tertiary level education and school completion (Hyman, 2017). A few assistance programmes, such as free textbooks, are given to all students in government schools regardless of students' socioeconomic status. The assistance programmes can be divided into two main categories, i.e., direct assistance and indirect assistance. Direct assistance is assistance that the students receive and benefit from directly, which includes textbooks, meals, scholarships, and free transportation (i.e., free bus trips to school). Indirect assistance is assistance that is distributed to the students through their parents or guardians, often making the students' individual and family circumstances as the programme's eligibility requirements. Students may not benefit directly from indirect assistance because it may be used by their parents or guardians for other purposes besides fulfilling the students' schooling needs.

Measuring academic achievement is challenging when it is done across numerous schools because every school has its own school-level assessment, which means that the assessment used may vary although the curriculum is standard. Test scores may not reflect the students' actual achievement level since individual achievement may rise and fall throughout the study years. Furthermore, a student's success is not merely indicated by test scores but may also extend to external factors, such as the school climate, and internal factors, such as the student's attitude. With these considerations in mind, this study proposed an alternative measurement of academic achievement by exploring students' academic optimism as an indicator of success.

Academic optimism is a composite measure of three main components, i.e., students' trust in teachers, academic press, and students' identification with their school. Hoy et al. (2006) initially introduced this concept as a response to Coleman's (1966) report which suggested that 
socioeconomic status, demographic attributes, and past achievements do not strongly influence present academic achievement. Instead, Hoy and his colleagues used theories proposed by earlier researchers-including Albert Bandura's social cognitive and self-efficacy theories, James Coleman's social capital theory, and Martin Seligman's study of learned optimism - to formulate a latent variable that can collectively explain academic success. They defined it as a measure consisting of three dimensions, namely collective teacher efficacy, academic emphasis, and faculty trust in students. In other words, academic optimism is the extent to which the school believes it can teach even the most difficult students, how much it trusts its students and their parents, and how much the school values academic success. These constructs were earlier validated by Adams and Forsyth (2011) and Tschannen-Moran et al. (2013).

\section{Research Questions}

Given its concern about urban poverty and government assistance programmes and their likely influence on students' academic optimism, the study posed the following research questions:

1. What is the underlying structure of urban poverty as perceived by urban poor students?

2. Is there a direct and significant relationship between urban poor students' perceptions of poverty and their academic optimism?

3. Does the government assistance students received influence their academic optimism?

4. Do urban poor students' perceptions of poverty influence their academic optimism?

5. Does government assistance mediate the relationship between urban poor students' perceptions of poverty and their academic optimism?

\section{Research Hypotheses}

In alignment with the literature review, the following hypotheses were formulated:

H1: Urban poor students' perceptions of poverty are correlated with their perceptions of government assistance.

H2: Urban poor students' perceptions of government assistance will influence their academic optimism

H3: Urban poor students' perceptions of poverty will influence their academic optimism

H4: Students' perceptions of government assistance will mediate the relationship between their perceptions of poverty and academic optimism 


\section{METHODOLOGY}

\section{Research Design and Method}

The design for the present study was ex-post facto or after-the-fact investigation, which refers to research undertaken to explore and examine a certain phenomenon within a sample or a population after the phenomenon has naturally occurred without the researcher's interference or experimental manipulation. The method chosen for the investigation was the cross-sectional survey through which cross-sectional data were acquired from a sample of urban poor students.

\section{Population and Sampling}

The data for this study were obtained from 500 urban poor secondary school students from Kuala Lumpur and Johor Bahru. The schools were selected with the assistance of the two cities' State Education Departments (i.e., Jabatan Pendidikan Negeri or JPN). To help the researchers understand the government assistance rendered to the urban poor, the relevant JPN staff briefed the research team about the types of assistance available for the students. A list of schools in Kuala Lumpur and Johor Bahru most affected by urban poverty was then drafted. From this list, only Form 4 students from the shortlisted urban poor families were randomly selected to participate in the survey.

\section{Survey Respondents}

Almost an equal percentage of male $(47.6 \%)$ and female students $(52.4 \%)$ were randomly selected for this study. Most of them (97\%) were 16 years of age. Malay respondents made up the majority $(65.4 \%)$, while the rest were from other ethnicities (i.e., Chinese, Indian, and other races). More than half of the respondents lived in Kuala Lumpur (57.8\%), while the rest in Johor Bahru (42.2\%). The sample size was adequate for the application of dimensionality analysis and structural equation modelling (SEM) to address the research questions and objectives.

\section{Instrumentation}

A self-reported 18-item questionnaire measuring urban poverty was used as the instrument. The items were partly self-developed based on the studies on poverty and social exclusion done in the UK. The survey is meant to be filled out by the adult who is head of the household (PSE, 2012). For this study, the items were adapted as they had to be answered by secondary school students themselves. Items related to household finances and expenditure and the family's economic well-being were revised for the intended young audience. Three experts in language and questionnaire design helped to refine the items for the Malaysian secondary school context. The items measuring student perceptions of urban poverty as a construct were developed by the research team and consisted of statements measuring the Causes of Poverty, Society's View (of 
people living in poverty), and Economic Effects (of poverty). The items were empirically tested a few times before being selected into the present study.

The second construct, Government Assistance, measured the students' perceptions of government financial assistance that they and their families received. The final construct, students' academic optimism, is a well-established construct that has been empirically validated by previous researchers (Adams \& Forsyth, 2011; Tschannen-Moran et al., 2013). Student academic optimism brings together three smaller concepts under one main construct, i.e., students' trust in teachers, academic press, and students' identification with their schools. Tschnannen-Moran et al. (2013) found that student academic optimism has a more significant impact on academic achievement than socioeconomic status. The reliabilities of all three measures were judged acceptable as they reached the threshold of 0.70 for social science constructs (i.e., 0.93 for students' academic optimism, 0.70 for government assistance, and 0.73 for student perceptions of urban poverty) (Nunnally \& Bernstein, 1994).

\section{Data Collection and Screening}

The survey respondents were urban upper secondary school students from two major Malaysian cities, i.e., Kuala Lumpur and Johor Bahru. Self-administered questionnaires were distributed to students within the sample populations in the current study. The process of data collection was done manually and involved distributing copies of the questionnaire to the sample and collecting them once they were completed. Sekaran and Bougie (2013) stressed that such an approach can create a bond between the researcher and respondents and motivate the latter to respond to the survey. Furthermore, it enables the researcher to address all questions about the study on site. Also, it is cost-efficient when administered to a group of respondents and usually yields a high response rate.

An important step before a quantitative data analysis is getting the data ready for the statistical procedures. This step is called data screening performed in SPSS. In the present study, it involved two main steps necessary for ensuring that the data were correctly entered and free of missing values and outliers. First, the extent of missing information present in the data set was examined, resulting in 100 cases of missing values being identified and deleted from the subsequent analysis. These cases had to be removed from the analysis because the respondents had failed to provide answers to more than 15 per cent of the questions, which meant that the number of missing values per observation had exceeded the threshold of $15 \%$ as recommended by Hair et al. (2013). The deletion left the data set with 500 usable responses out of 600 total responses.

For outlier detection, each variable was examined for the standardised (z) score (Tabachnick \& Fidell, 2012). Following Hair et al. (2010), a case is considered an outlier if its standardised $\mathrm{Z}$ score is \pm 4.0 or beyond. Therefore, any Z-score greater than 4 or less than -4 is categorised as an outlier. The results indicated that the standardised (z) scores were less than \pm 4 for all items. Thus, the data set containing the 500 cases was judged free of outliers. 


\section{Data Analysis}

The study first performed a dimension reduction analysis using Principal Components Analysis (PCA) to extract the underlying structure of students' perceptions of urban poverty. Next, a three-stage Structural Equation Modelling (SEM) using the AMOS model-fitting programme (version 24) was applied to validate the measurements of both perceived urban poverty and students' academic optimism as well as to test the influence of the former on the latter construct (i.e., academic optimism). The study employed confirmatory factor analysis (CFA) and a fullfledged SEM to verify the adequacy of the hypothesized measurement model and the structural model. The hypothesized models were estimated using the covariance matrix derived from the data. Thus, the estimation procedures employed satisfied the underlying statistical distribution theory, hence yielding estimates of defensible properties.

collectively), homoscedasticity (fairly rectangular and concentrated around the center, as shown by the plot of residuals against the standardized predicted values in Figure 2), no multicollinearity and significant outliers, and the residuals are approximately normally distributed as confirmed from the P-P plot in Figure 3.

\section{RESULTS}

\section{Underlying Structure of Urban Poverty as Perceived by Urban Poor Students}

A PCA with the Varimax rotation method and maximum likelihood extraction procedure was conducted to explore the underlying structure of urban poverty as perceived by the sample of 500 Form Four students from the urban poor category. The results showed an acceptable degree of intercorrelation among the 18 questionnaire items and reasonable factorability of the data that justified the employment of PCA. The Kaiser-Meyer-Olkin measure of sampling adequacy was .64, just slightly above the commonly recommended value of .6, and Bartlett's test of sphericity was significant $(\chi 2(36)=551.650, p=.001)$. Table 1 presents the inter-item correlation matrix where the items appeared to be moderately correlated with very few items exceeding the value of 0.3 , thereby fulfilling yet another requirement for EFA.

\section{Table 1}

Inter-Item Correlation Matrix

\begin{tabular}{lccccccccc}
\hline & Cause3 & Cause4 & Cause5 & Soc1 & Soc3N & Soc6 & Econ3 & Econ4 & Econ6N \\
\hline Cause3 & 1.000 & & & & & & & & \\
Cause4 & .374 & 1.000 & & & & & & & \\
Cause5 & .359 & .412 & 1.000 & & & & & & \\
Soc1 & -.059 & .011 & .025 & 1.000 & & & & & \\
Soc3N & -.021 & .043 & .111 & .205 & 1.000 & & & & \\
Soc6 & .033 & .077 & .179 & .290 & .380 & 1.000 & & & \\
Econ3 & .149 & .212 & .133 & .038 & .103 & .050 & 1.000 & & \\
Econ4 & .102 & .152 & .168 & -.052 & .091 & -.089 & .129 & 1.000 & \\
Econ6N & .104 & .134 & .090 & .070 & .123 & .054 & .468 & .171 & 1.000 \\
\hline
\end{tabular}


As expected, the PCA extracted three underlying factors of perceived urban poverty. The reproduced correlation matrix appeared to best fit the intercorrelation among the indicators, accounting for $55 \%$ of the total variance. The first extracted dimension (i.e., Causes of Poverty), had the largest eigenvalue at 2.16, while the eigenvalues of the other two dimensions were 1.56 and 1.27, respectively, for Society's Views and Economic Effects of Urban Poverty. A Monte Carlo parallel analysis (Matsunaga, 2010) was conducted, and the results supported the existence of a three-factor solution in the data set.

Performing Principal Components Analysis as the extraction method and Varimax as the rotation method on the 18 items, while suppressing the factor loading to 0.4 , yielded only nine items forming a three-factor structure. This means that only nine items from the original 18item pool could be used for the full study. The other nine items did not survive the suppressed factor loading, where three items from each construct were dropped in the subsequent analysis. One item under Economic Effects, i.e., Econ4, was retained despite its low factor loading (.402) to ensure that enough items were used to represent the construct. Deleting the item would affect the reliability of Economic Effects as a latent dimension of Perceived Urban Poverty as suggested by theory. Furthermore, Hair et al. (2010) consider factor loadings between \pm 0.3 to \pm 0.4 as the minimum acceptable level for item retention. Table 2 shows the extracted factor structure for Perceived Urban Poverty along with each dimension's eigenvalues and variance explained.

Table 2

Factor Loadings, Eigenvalues and Variance Explained for All Variables

\begin{tabular}{cccc}
\hline \multirow{2}{*}{ Items } & \multicolumn{3}{c}{ Extracted Component } \\
\cline { 2 - 4 } & Causes of Poverty & Society's Views & Economic Effects \\
\hline Cause5 & .777 & & \\
Cause3 & .747 & & \\
Cause4 & .745 & .799 & \\
Soc6 & & .696 & \\
Soc3N & & .660 & .847 \\
Soc1 & & & .797 \\
Econ6N & & & .402 \\
Econ3 & & $\mathbf{1 . 5 6 1}$ & $\mathbf{1 . 2 7 1}$ \\
Econ4 & $\mathbf{2 . 1 6 3}$ & $\mathbf{1 7 . 3 4 1}$ & $\mathbf{1 4 . 1 2 7}$ \\
\hline Eigenvalues & $\mathbf{2 4 . 0 3 8}$ & $\mathbf{4 1 . 3 7 9}$ & $\mathbf{5 5 . 5 0 6}$ \\
\% of Variance Explained & $\mathbf{2 4 . 0 3 8}$ &
\end{tabular}

Note. Factor loadings $<.4$ were suppressed.

\section{Measuring the Validity of Students' Perceptions of Urban Poverty}

To test the multidimensionality of students' perceptions of urban poverty as a construct, a CFA was applied to the data drawn from the sample of 500 Form Four urban poor students. Figure 2 shows the results of the estimated measurement model indicating that the three-factor structure of perceived urban poverty was adequate to represent the data. The goodness-of-fit of the model 
was reasonable, the relative Chi-square $=2.391 ; \mathrm{RMSEA}=.053 ; \mathrm{CFI}=.938$. There was no evidence that the measurement model of students' perceptions of urban poverty was incorrect.

\section{Figure 2}

CFA Results Confirming a Three-Factor Structure of Students' Perceptions of Urban Poverty

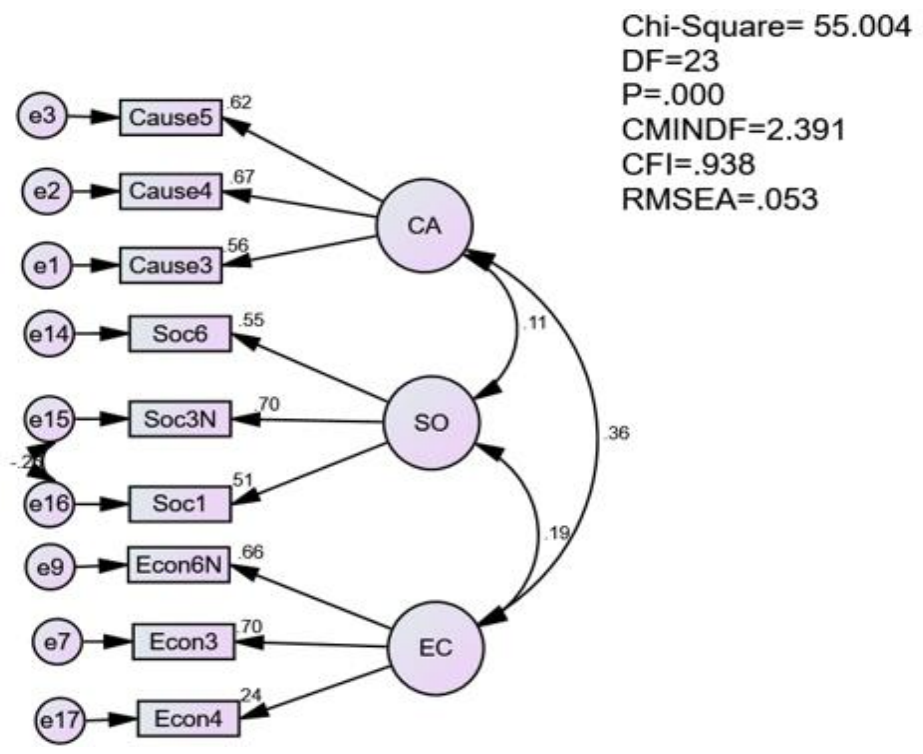

\section{Measuring the Validity of Academic Optimism}

To test the multidimensionality of the Academic Optimism measure, a CFA was similarly applied to the data drawn from the same sample. The results of the estimated measurement model, indicated in Figure 3, show that the three-factor structure of Academic Optimism was adequate to represent the data. The goodness-of-fit of the model was reasonable; the relative Normed Chi-square $=2.633 ; \mathrm{RMSEA}=.057 ; \mathrm{CFI}=.95$.

\section{Figure 3}

CFA Results Confirming a Three-Factor Structure of Academic Optimism

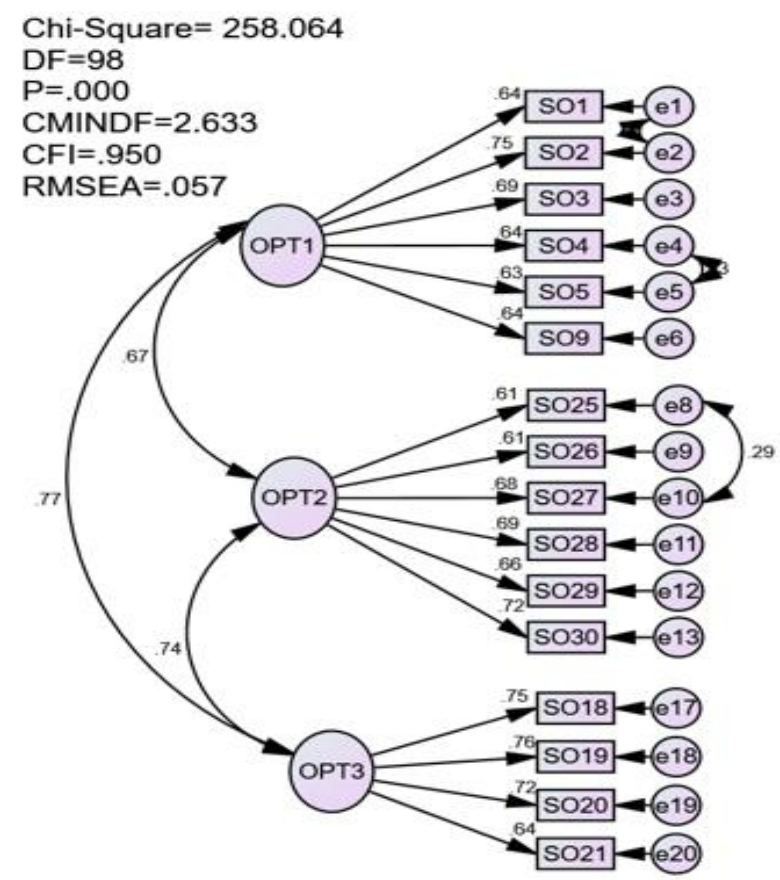




\section{Adequacy of the Hypothesised SPP-GA-SO Structural Model}

Figure 4 summarises the Structural Equation Modelling results testing the causal relationships among students' perceptions of urban poverty, government assistance and academic optimism that addressed the third and fourth research hypotheses. The structural model showed consistency of the hypothesised causal relationships with the data (Chi-square $=737.699$; RMSEA $=.049 ;$ CFI $=.908$; Normed Chi-square $=2.196$ ). All the fit indices satisfied their critical cut-scores. The results, therefore, indicated a fitting model of the causal relationship between students' perceptions of urban poverty and academic optimism via government assistance. The parameter estimates of the hypothesised model were free from offending values with uncorrelated errors.

\section{Figure 4}

SEM Results of the Hypothesised SPP-OPTM Model

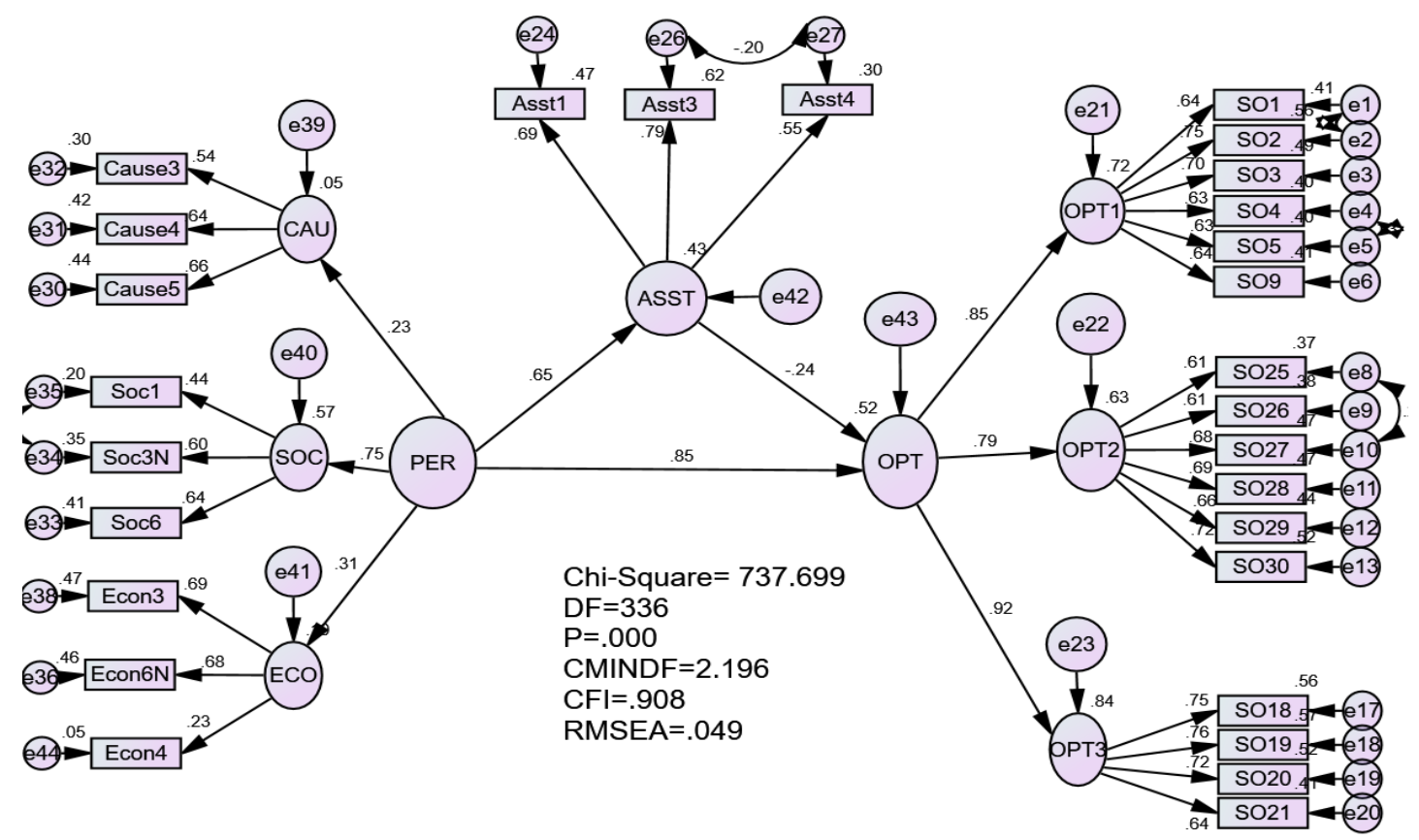

Table 3 summarises the results of the SEM analysis. Two path coefficients of the causal structure were statistically significant at the .01 level and were of practical importance. First, the standardised path coefficient of students' perceptions of urban poverty $\rightarrow$ government assistance was substantial and statistically significant with $\beta=0.66$. Second, the standardised path coefficient of government assistance $\rightarrow$ students' academic optimism was neither substantial nor statistically significant, even though the $\beta$ value was -0.23 , the $p$-value was .318 and the $t$-value was -.998 . Third, the standardised path coefficient between students' perceptions of urban poverty and academic optimism was substantial and statistically significant with $\beta=$ 0.84 .

Finally, the indirect causal relationship between students' perceptions of urban poverty and academic optimism via government assistance was not supported by the data, even though the path coefficient was .157 and above the threshold of 0.08 . The study's hypothesis was not 
supported as the t-value was -.578 and the $p$-value was .562 . This result was expected since the relationship between government assistance and academic optimism was also not supported by the data.

\section{Table 3}

Results of Testing the Hypothesised Model

\begin{tabular}{llccccc}
\hline \multicolumn{1}{c}{ Hypotheses } & $\boldsymbol{\beta}$ & S.E & $\begin{array}{c}\text { T-value } \\
(>\mathbf{1 9 6})\end{array}$ & $\begin{array}{c}\text { P-value } \\
(<.05)\end{array}$ & Result \\
\hline $\mathrm{H} 1$ & $\mathrm{SPP} \rightarrow$ ASST & 0.660 & 1.050 & 2.787 & 0.005 & Supported \\
$\mathrm{H} 2$ & $\mathrm{ASST} \rightarrow$ OPT & -0.238 & 0.160 & -0.998 & 0.318 & Not supported \\
$\mathrm{H} 3$ & $\mathrm{SPP} \rightarrow$ OPT & 0.846 & 1.175 & 2.173 & 0.030 & Supported \\
$\mathrm{H} 4$ & $\mathrm{SPP} \rightarrow$ ASST $\rightarrow$ OPT & 0.157 & 0.271 & -0.578 & 0.562 & Not supported \\
\hline
\end{tabular}

\section{DISCUSSION}

The results have produced empirical evidence supporting $\mathrm{H} 1$ - which predicted a substantial and statistically significant causal relationship between students' perceptions of urban poverty and government assistance. This discovery is consistent with the findings of Hassan and Rasiah (2011) on education expenditure among Malaysian school students. Both studies offer evidence for a more equitable distribution of assistance that should aim to produce better academic outcomes among students of all backgrounds.

Malaysia's economic growth has not only led to better economic activities for the people, but it has also enabled the country to provide sufficient subsidies to the needy, enabling them to reduce and overcome crippling socioeconomic inequalities. Government assistance and financial aid schemes are measures taken by the Malaysian government to alleviate poverty and improve the overall wellbeing of the population.

Indeed, an economic growth that does not represent 'growth with distribution' should be avoided as it can eventually lead to detrimental effects, especially on the wellbeing of the lowerincome segment of the population. The economic growth a country experiences should contribute to an economic development that encompasses the element of 'inclusivity' found in the results of this study. The findings also indicate that government assistance may have been distributed accordingly to the needful schools.

The second research hypothesis, H2, which predicted the relationship between government assistance and academic optimism, was not supported by the data as the predicted association was not statistically significant. There appears to be a gap in understanding how assistance can improve academic optimism. This is an area that needs further investigation since assistance programmes differ from school to school, state to state and country to country. Issues such as distribution and effectiveness are fruitful topics for interested researchers. More 
importantly, the nature and effectiveness of government assistance provided to schools are worth investing.

On the other hand, the findings reveal an interesting point and concur with other studies. The common assumption related to the economic growth experienced in Malaysia over the decades has not been translated into successfully specific academic support programmes in schools. However, previous studies (e.g., Hoy et al., 2006; Tschannen-Moran et al., 2013) have shown that academic optimism, particularly collective academic optimism, is the outcome of the concerted efforts of both parents and school citizens in achieving academic performance. This finding indicates that academic optimism is not influenced by economic factors that tend to impair student achievement (Hoy et al., 2006). This finding is also similar to Hoy et al.'s (2006) finding that shows the critical nature of academic optimism. Although Hoy et al.'s study showed that academic optimism is related to higher academic outcomes among students, this may not necessarily be true for government assistance.

Meanwhile, Tschannen-Moran et al. (2013) found a significant negative relationship between academic optimism and socioeconomic status, which was represented by the percentage of students eligible for the free and reduced lunch programme, i.e., a form of government assistance placed in schools. According to Seligman (1998, cited in Hoy et. al. 2006), "learned optimism may push people to move beyond learned pessimism, overcoming learned helplessness, thus breaking the cycle of self-fulfilling and defeating prophecy" (p. 440). Seligman's argument points to the possibility that socioeconomic status may not be as influential as many would assume. Perhaps this explains why academic optimism is not significantly related to government assistance since schools are resourceful enough to achieve their desired academic performance independent of government assistance programmes.

The third hypothesis, H3, which tested the relationship between urban poor students' perceptions of poverty and academic optimism, was substantial and statistically significant. This result is in line with Khoo et al. (2017), whose findings suggested that urban poor schools do exhibit a high level of academic optimism. As explained by Seligman in the preceding discussion, urban poor schools are related significantly to academic optimism due to the forceful construct of individual and collective optimism, which has the potential to generate favourable student performance. With the right opportunity, urban poor students could perform better and be more academically optimistic about their achievement. In line with Seligman's argument, the finding also indicates that socioeconomic factors may not be the determining factors of academic optimism.

Finally, H4, which tested the indirect relationship between urban poor students' perceptions of poverty and academic optimism through government assistance, was not supported by the results. This is expected since $\mathrm{H} 2$, which predicted the direct influence of government assistance on academic optimism, was rejected earlier. The finding further suggests that the existing support programmes and assistance need to be reviewed and mechanisms to find a more effective government support assistance to increase and uplift academic optimism among students need to be proposed. 


\section{Implications and Recommendations}

The results of this study have critical implications for school leadership in urban poor schools. Leaders at these schools have to deal with the unique challenges of urban poverty and academic optimism among students. The success of these schools would depend on strong leadership and good management practices that understand the problems, dilemmas and challenges faced by poor students. To achieve that aim, it is vital for the leaders of urban poor schools to play their roles as effective instructional leaders. Effective instructional leaders are school leaders who are successful in promoting self-reflection and professional development among their teachers (Blase \& Blase, 2000). Among the measures that school leaders can take to become effective instructional leaders are providing opportunities for teacher training and skills development, engaging teachers as partners in fruitful, reflective dialogues and employing several types of strategies to engage teachers and staff. They should also consider these measures with respect to the context of their school (Hallinger, 2005), as each school has its specific challenges and needs. In this condition, leaders are expected to inspire and guide teachers to adopt a high level of organisational citizenship behaviours where teachers or counsellors should be able to help students beyond their routine job description and after school hours.

Furthermore, educational leaders at the federal, state and school levels are recruited not only for their knowledge, skills and attitudes, but also on the account of their capacities to be flexible, adaptable, creative and amendable to change. This requires educational leaders to enhance their expertise, capability and understanding to support student learning in poor urban schools. In some cases, educational officers are appointed to posts with little or no training to manage diversity in the workplace. There is also a need to address social and racial issues in the government assistance programme delivery process as students also carry with them social stigmas and prejudices that they observe in their daily lives (Bonaker, 2019). Khoo et al. (2018) argued that given the multicultural structure of societies such as that in Malaysia, ethnic background should be taken as a major consideration in addressing the issue of poverty and in the efforts taken to eradicate it. In the current climate of pressure and accountability, staff development programmes should assist educational leaders in developing teaching strategies as well as providing the mechanisms to improve student learning, participation and academic optimism among urban poor students. Ladson-Billings (2017) argued that teachers' selfefficacy could help turn the situation around for these underprivileged students.

To address the above findings, the researchers would like to suggest the following plan of action:

1. The government should re-evaluate the policy on financial assistance for poor students. One of the most effective ways to help poor students is by giving vouchers for them to buy books or food and to spend on other education expenses. This method is practical to ensure that the assistance will be used for student education and to avoid misuse of financial assistance by parents. The government and schools should establish a solid partnership with parents and the community. This policy should enhance participation from community leaders and parents to help poor urban students. 
3. School leaders from different urban poor schools should engage in collaboration. They should form teams that can discuss the strategies used and learn from one another the strategies that have been successfully implemented at other schools.

4. At the school level, teachers need to monitor and assess the effectiveness of the strategies used. They should also consider other strategies as the challenges may differ according to students' grade level and cohort.

5. While assistance programmes could lessen the financial burden of the families of the urban poor, their effectiveness in terms of helping the recipients during critical times should be further investigated.

6. Urban poor students should be given several options in completing their secondary-level education, either via scholarships and financing or via opportunities for skills-based training that could increase their employability. Becoming skilful and employable would allow them to contribute to their family's household income and potentially bring them out of the poverty cycle.

7. Technology can be very instrumental in the efforts to help urban poor students. The use of a regularly updated student database can provide decision-makers with the most current and comprehensive data to help them to formulate policies and plan assistance programmes. In addition to this database, free, easy to use and widely available apps can become channels of communication between teachers and parents.

\section{CONCLUSION}

The Malaysian government has channelled millions of ringgits into numerous assistance programmes, targeting thousands of poor students, both urban and rural. However, the findings of the present study suggested that government assistance programmes were not instrumental in improving urban poor students' overall academic optimism. On the other hand, despite their challenging living circumstances, the urban poor students demonstrated a healthy level of academic optimism.

Students in the urban poor category hold an encouraging outlook of their schooling experience, suggesting that the mainstream education system in Malaysian government schools does have a positive impact on the urban poor students. This finding is noteworthy considering the detrimental effects urban poverty can have on students and their learning (Silva-Laya et al., 2020). Finally, it is worth noting that the urban poor students do not consider the assistance programmes to be instrumental in shaping their academic optimism. They understood why they needed assistance but did not see how such assistance could lead to their success in school. Since these assistance programmes are funded by taxpayers' money, there is a definite need to evaluate the programmes further in terms of effectiveness and efficiency. 


\section{REFERENCES}

Adams, C. M., \& Forsyth, P. B. (2011). Student Academic Optimism: Confirming A Construct. In M. F. DiPaola, \& P. B. Forsyth (Eds.), Leading Research in Educational Administration: A Festschrift for Wayne K. Hoy (pp. 73-87). Information Age Publishing.

Aziz, N. (2015). Poverty Eradication: A View from the Malaysian Parliament. (JOBSTS) Journal of Borneo Social Transformation Studies, 1(1), 52-64.

Beauvais, K. (1993). Children's voices: Influences on the formation of educational aspirations in economically disadvantaged, urban Black children (Unpublished doctoral dissertation). https://www.elibrary.ru/item.asp?id=5729853

Blase, J., \& Blase, J. (2000). Effective instructional leadership: Teachers' perspectives on how principals promote teaching and learning in schools. Journal of Educational Administration, 38(2), 130-141.

Bonaker, A. (2019). School Lunch and Social Inclusion in the Context of Urban Poverty. https://edoc.hu-berlin.de

Cabinet Office (2008). Aspiration and Attainment Amongst Young People in Deprived Communities. Retrieved from https://lx.iriss.org.uk/content/aspiration-and-attainmentamongst-young-people-deprived-communities-analysis-and-discussion-.

Capra, T. (2009). Poverty and its impact on education: Today and tomorrow. Thought \& Action, Fall 2019, 75-81.

Chang, D. C. (2008). A case study to determine what perceived factors, including student engagement, contribute to academic achievement in a high performing urban high school (Unpublished doctoral dissertation). https://www.semanticscholar.org/

Che Mat, N. (2017). Mengurangkan bilangan murid berisiko keciciran sekolah melalui intervensi modul pendekatan psikologi kaunseling. Jurnal Psikologi dan Kaunseling, 8, $1-18$.

Coleman, J. (1966). The concept of equality of educational opportunity. Harvard Educational Review, 38(1), 7-22.

Economic Planning Unit (2004). Malaysia: 30 years of poverty reduction, growth and racial harmony. http://documents.worldbank.org/curated/en/839661468758680322 /Malaysia30-years-of-poverty-reduction-growth-and-racial-harmony.

Economic Planning Unit (2018). Eleventh Malaysia Plan, 2016-2020. Retrieved from http://www.epu.gov.my/en/rmk/eleventh-malaysia-plan-2016-2020.

Garland, A. M., Massoumi, M., \& Ruble, B. A. (2007). Global Urban Poverty. Washington: Woodrow International Center for Scholars.

Gehrke, R. S. (2005). Poor schools, poor students, successful teachers. Kappa Delta Pi Record, 42(1), 14-17.

Gürol, M., \& Kerimgil, S. (2010). Academic optimism. Procedia-Social and Behavioral Sciences, 9, 929-932. 
Hair, J. F., Black, W. C., Babin, B. J., \& Anderson, R. E. (2010). Multivariate Data Analysis (7th ed.). Pearson.

Hair, J. F., Hult, G. T. M., Ringle, C., \& Sarstedt, M. (2013). A Primer on Partial Least Squares Structural Equation Modeling (PLS-SEM). SAGE Publications.

Hallinger, P. (2005). Instructional leadership and the school principal: A passing fancy that refuses to fade away. Leadership and Policy in Schools, 4(3), 221-239.

Hatta, Z. A., \& Ali, I. (2013). Poverty reduction policies in Malaysia: Trends, strategies and challenges. Asian Culture and History, 5(2), 48-56.

Hassan, O., \& R. Rasiah, R. (2011). Poverty and Student Performance in Malaysia. Institutions and Economies, 3(1), 61-76. https://ijie.um.edu.my/index.php/ijie/ article/view/ 4776.

Hong, F. Y. (2017). Antecedent and consequence of school academic optimism and teachers' academic optimism model. Educational Studies, 43(2), 165-185.

Hoy, W. K., Tarter, C. J., \& Hoy, A. W. (2006). Academic optimism of schools: A force for student achievement. American Educational Research Journal, 43(3), 425-446.

Hyman, J. (2017). Does money matter in the long run? Effects of school spending on educational attainment. American Economic Journal: Economic Policy, 9(4), 256-80.

Khoo, S. L., Mohamad Shaharudin Samsurijan, P. S. Gopal, Nor Malina Malek, \& Zahri Hamat (2018). Urban poverty alleviation strategies from multi-dimensional and multi-ethnic perspectives: Evidences from Malaysia. Kajian Malaysia, 36(2), 43-68.

Ladson-Billings, Gloria. (2017). "Makes Me Wanna Holler": Refuting the "Culture of Poverty" Discourse in Urban Schooling. The ANNALS of the American Academy of Political and Social Science. 673. 80-90.

Liddle, B. (2017). Urbanization and inequality/poverty. Urban Science, 1(4), 1-7.

Mathur, O. P. (2013). Urban Poverty in Asia. Asian Development Bank.

Matsunaga, M. (2010). How to factor-analyze your data right: Do's, don'ts, and how-to's. International Journal of Psychological Research, 3(1), 97-110.

Mok, T. Y., Gan, C., \& Sanyal, A. (2007). The determinants of urban household poverty in Malaysia. Journal of Social Sciences, 3(4), 190-196.

Nunnally, B., \& Bernstein, I. R. (1994). Psychometric Theory. McGraw-Hill.

PSE (2012). PSE UK 2012: Living standards questionnaire with top-level results. http://www.poverty.ac.uk/pse-research/questionnaires.

Ravallion, M. (1997). Good and bad growth: The human development reports. World Development, 25(5), 631-638.

Sekaran, U., \& Bougie, R. (2013). Research Methods for Business: A Skill-Building Approach ( $6^{\text {th }}$ ed.). John Wiley $\&$ Sons. 
Sezgin, F., \& Erdogan, O. (2015). Academic optimism, hope and zest for work as predictors of teacher self-efficacy and perceived success. Educational Sciences: Theory and Practice, 15(1), 7-19.

Silva-Laya, M., D'Angelo, N., García, E., Zúñiga, L., \& Fernández, T. (2020). Urban poverty and education. A systematic literature review. Educational Research Review, 29, 100280.

Tabachnick, B. G., \& Fidell, L. S. (2012). Using Multivariate Statistics (6 $6^{\text {th }}$ ed.). Pearson.

Tafere, Y. (2012). Children's experiences and perceptions of poverty in Ethiopia. Young Lives.

Tschannen-Moran, M., Bankole, R. A., Mitchell, R. M., \& Moore Jr, D. M. (2013). Student Academic Optimism: A Confirmatory Factor Analysis. Journal of Educational Administration, 51(2), 150-175. 